\title{
Disability claims on psychiatric grounds in the South African context: A review
}

\author{
Matlhodi T Mokoka, BSc, MB ChB, MMed (Psych) \\ Solomon T Rataemane, MB ChB, Dip Child Psychiatry (UK), FFPsych (SA) \\ Department of Psychiatry, University of Limpopo, Medunsa Campus
}

Monika dos Santos, PhD (Psy)

Foundation for Professional Development, Lynwood Ridge, Pretoria

\begin{abstract}
We review the nature of disability claims on psychiatric grounds in the South African context, including factors contributing to disability claims, specific disorders usually leading to disability claims, impairment and disability, assessing the degree of impairment, guidelines in assessing psychiatric disability, ethical considerations, consequences of medical boarding, and rehabilitation. Psychiatrists should consider the potential benefits of supervised and mentored work rehabilitation programmes, graded return to work or an appropriate alternative position in consultation with employers.

S Afr J Psych 2012;18(2):34-41.
\end{abstract}

Psychiatric disorders as a cause of occupational disability are under-recognised and under-treated worldwide., ${ }^{1,2}$ In Canada, disability claims related to psychiatric disorders have doubled in recent years, accounting for $30 \%$ of all disability claims at a cost of billions of dollars annually. ${ }^{3}$ In Finland, $17 \%$ of all disability pensions to men were due to a psychiatric disorder, of which 53\% were for depression. ${ }^{4}$ In South Africa there has been a similar alarming increase in applications for medical disability on psychiatric grounds, related in many cases to socio-political changes, ${ }^{5}$ and psychiatric disorders have taken over from musculoskeletal conditions, particularly lower back pain, as the leading cause of disability. ${ }^{6}$ People in jobs with high social and ethical responsibility, such as in the police force, the military and teaching, may be at particular risk for developing stress-related disorders. ${ }^{7}$ Among these disorders, depression, anxiety and posttraumatic stress disorder head the list.

Psychiatrists are being put under increasing pressure to declare patients impaired on psychiatric grounds. The need for guidelines in assessing psychiatric disability claims in a practical and consistent way has been expressed for some time by all parties involved, i.e. psychiatrists and insurance companies, as well as employers and patients. $^{8}$
The need for a standardised approach to the assessment of patients with psychiatric disorders for medical disability was initially addressed in 1995 by a task team comprising nominated psychiatrists from the South African Society of Psychiatrists (SASOP) and medical advisors of the Life Offices Association (LOA). Subsequently, a task team of psychiatrists appointed by SASOP collaborated with medical practitioners representing the LOA in revising the original guidelines. The resulting second edition was drawn up by the participants, distributed widely for comments, and approved by the executive committee of SASOP.

\section{Factors contributing to disability claims Administrative and procedural delays}

A striking factor in a study of teachers in the northern provinces of South Africa requesting early retirement on psychiatric grounds, not mentioned in a Cape study of teachers claiming occupational disability due to work-related stress, ${ }^{10}$ was that several applicants had been receiving full salaries while off work on sick leave for 4 or more years, before going for independent assessment and final adjudication of their claims.

The American College of Occupational and Environmental Medicine (ACOEM) guideline 'Preventing needless work disability by helping people stay employed' indicates that 'administrative or procedural delay in instituting appropriate management' is included in the list of 'medically unnecessary factors contributing to long term disability.'11

Clearly the problem of administrative or procedural delay is not peculiar to South Africa. It is nonetheless of major concern in this country that inefficiency in various education, government and municipal departments, particularly the South African Police Service and the Department of Correctional Services, makes it impossible for applications for disability, temporary or permanent, to be processed within reasonable periods of time.

\section{Ergophobia ('work phobia')}

Aversion to perceived adverse elements of the workplace is very common among claimants for disability on psychiatric 
grounds, regardless of occupation. It is probably the major factor in preventing successful return to work. The phenomenon is obscured by the ubiquitous wild-card term 'stress', which is used to describe the situation at work, the mechanism by which it impinges on patients' functionality, and the mental illness of the patient. Shiels et al. suggest that mild mental disorder such as 'stress' is being increasingly accepted as a legitimate cause of sickness, in spite of our very justifiable concern about the adverse effects of stigma surrounding psychiatric illness. ${ }^{12}$ Van der Klink et al. found that adjustment disorders accounted for most psychopathology giving rise to inability to work in the Netherlands, ${ }^{13}$ and would often be an appropriate diagnosis in the early stages of exit from work.

\section{Issuing of sick-leave certificates}

It is worrying when a treating psychiatrist issues a certificate stating that the patient must have sick leave for 6 or 12 months (at the end of which time, if recovery has not taken place, medical boarding may be recommended). Overseas studies revealed that few patients who have had sick leave for 6 months will ever return to the open labour market, and the situation may be similar in South Africa - or even worse, considering the scarcity of employment opportunities. Moreover, financial secondary gain factors affect rates of recovery from illness and eventually clinical outcome in a wide variety of situations. $^{14,15}$

Perhaps most worrying is the fact that in South Africa sick-leave certificates for a prolonged period off work are increasingly being issued by psychologists and traditional healers as part of the management of common psychiatric disorders..$^{10}$ The adverse economic consequences for employers and health systems are significant, as is the pressure on colleagues who have to cope with the sick worker's absence. ${ }^{16,17}$

Many doctors, including psychiatrists, appear to be unaware of the potential harm that medically excused prolonged time off work can cause the patient, ${ }^{12,14}$ for example psychological factors such as loss of identity and self-worth, deterioration in physical and psychological health, a reported sixfold increase in the rate of suicide, pressures on interpersonal relationships, financial hardship and general erosion of quality of life..$^{18}$

\section{Impairment and disability}

Impairment is the alteration of normal functioning due to a disease. It must be diagnosed, and treatment options thoroughly investigated, before determining on medical grounds which functions the person is still able to do and which not.

Disability is the alteration of capability to meet the personal, social or occupational demands due to an impairment, and is not assessed merely clinically.
The treating doctor involved only expresses his or her opinion on functional impairment due to the disease, and informs the patient that the decision on disability is made by a panel of experts appointed by the employers/insurers. ${ }^{8}$

\section{Assessment of degree of impairment}

The American Medical Association (AMA) Guidelines to the Evaluation of Permanent Impairment suggest four areas for assessing the severity of functional impairment in patients with psychiatric disorders: ${ }^{19}$

- Activities of daily living, such as self-care, personal hygiene, communication, ambulation, travel, sleep, sexual function, shopping, paying bills and recreation. It is important to assess not just the number of activities restricted, but the degree of restriction.

- Social functioning, which refers to the patient's capacity to communicate and interact effectively, for example the ability to get along with others, communicate clearly, participate in group activities, co-operate, and be aware of others' feelings. Impairment will result in altercations, aggressive outbursts, evictions, firing from work, fear of people, avoidance and social withdrawal.

- Concentration, persistence and pace determine a person's ability to sustain focused attention in order to complete tasks. This function is best assessed in the work situation. Some aspects can be tested in the mental status examination (for example serial 7s).

- Adaptation includes ability to adapt to the work environment and to stressful circumstances.

It is helpful to summarise the areas of dysfunction and estimate the degree of severity of impairment (absent, mild, moderate, marked or extreme impairment).

According to the Diagnostic and Statistical Manual of Mental Disorders, 4th edition, text revision (DSM-IV-TR), the Social and Occupational Functioning Assessment Scale (SOFAS) differs from the Global Assessment of Functioning (GAF) Scale in that it focuses exclusively on the individual's level of social and occupational functioning and is not directly influenced by the overall severity of psychological symptoms. Also in contrast to the GAF Scale, any impairment in social and occupational functioning due to general medical conditions is taken into account in the SOFAS rating. ${ }^{20}$ The scale consists of a continuum from excellent functioning to grossly impaired occupational and social functioning.

According to the Social Security Administration Regulations (SSA), evaluation of disability on the basis of mental disorders requires the 'generic list' of criteria for determination of impairment that can be applied to a particular case: ${ }^{21}$

- Paragraph A, document a medically determinable impairment(s) according to the DSM criteria

- Paragraph B, consider the degree of limitation that such impairment(s) may impose on the individual's ability to work, resulting in at least two of the following: 
- Marked restriction of activities of daily living; or

- Marked difficulties in maintaining social functioning; or

- Marked difficulties in maintaining concentration, persistence, or pace; or

- Repeated episodes of decompensation, each of extended duration; episodes of decompensation and deterioration are exacerbations or temporary increases in symptoms or signs accompanied by a loss of adaptive functioning, as manifested by difficulties in performing activities of daily living, maintaining social relationships, or maintaining concentration, persistence or pace. The term repeated episodes of decompensation, each of extended duration, in these listings means three episodes within 1 year, or an average of once every 4 months, each lasting for at least 2 weeks.

- Paragraph C can be an additional criterion to B or can be considered alone when $B$ is not satisfied:

Documented history of a chronic mental disorder of at least 2 years' duration that has caused more than a minimal limitation of ability to do basic work activities, with symptoms or signs currently attenuated by medication or psychosocial support, and one of the following:

- Repeated episodes of decompensation, each of extended duration; or

- A residual disease process that has resulted in such marginal adjustment that even a minimal increase in mental demands or change in the environment would be predicted to cause the individual to decompensate; or

- Current history of 1 or more years of inability to function outside a highly supportive living.

\section{General guidelines for psychiatric disability evaluation}

- Clarify the type of referral with the referral source.

- Obtain informed written consent.

- Review records and collateral information.

- Conduct a standard psychiatric examination, multi-axial diagnosis.

- Be familiar with the essential functions and training necessary for a patient's job.

- Seek descriptions and clear examples of impairment in relation to essential and non-essential job functions.

- Assess the degree of impairment (AMA, SSA, etc.).

- Correlate the mental disorder with occupational impairment.

- Assess complaints of impairments for internal consistency.

- Assess functional history and correlate it with the current level of impairment.

- Use rating scales when appropriate.

- Utilise psychological tests when appropriate.

- Consider alternatives that may account for claims of disability.

- Exclude the possibility of malingering.

- Formulate well-reasoned opinions, supported by clinical and psychiatric data, on whether the patient is temporarily or permanently impaired and suggest accommodations based on the degree of impairment.
- Write a comprehensive report that addresses the referral question. ${ }^{21}$

\section{Specific disorders usually leading to disability claims}

According to the SASOP Guidelines to the Management of Disability Claims on Psychiatric Grounds, ${ }^{8}$ decisions regarding the permanence of impairment must not be made lightly. A disorder should only be regarded as non-responsive or refractory to treatment after optimal treatment has been applied, i.e. optimal doses of the most effective medications for an adequate period, plus appropriate psychotherapy by a suitably qualified therapist. Treatments applied need to be generally recognised as appropriate for the psychiatric disorder in question as well as to be evidence based. Patient compliance is also important - a patient who does not keep psychotherapy appointments or does not take medication should not be reported as being non-responsive to treatment. 8

In the majority of cases of major depressive disorder (MDD) there is a remission of symptoms, and functioning returns to the pre-morbid level. An individual who has MDD is not considered disabled if he or she can engage in substantive gainful activity - as a rule of thumb, a disabled individual should not be able to participate actively in the national economy. The condition can only be regarded as refractory when optimal treatment has failed, after which permanent impairment can be considered. Although dysthymic disorders follow a chronic course and are often not dramatically responsive to treatment, the degree of associated impairment is usually not sufficient to cause permanent occupational disability. 22,23

Both manic and depressive episodes are often characterised by severe functional impairment. During remission most patients return to good functioning, although some experience residual core symptoms that account for continued functional impairment. There are three categories of bipolar mood disorder that may be considered for permanent disability, namely,patients with prominent residual symptoms, those with frequent relapses (rapid cyclers), and those in whose jobs the implications of a future relapse may be serious (e.g. airline pilot, judge).

In adjustment disorder, the degree of impairment is not severe enough to warrant permanent disability. When symptoms related to stressors are more severe or protracted, the patient will usually meet criteria for a major depressive disorder or another psychiatric disorder, and the guidelines for that disorder will apply. ${ }^{22-24}$

Post-traumatic stress disorder (PTSD) has become a common diagnosis given to patients applying for medical disability in South Africa. There have been cases of patients grossly exaggerating symptoms, as well as misrepresenting the severity of the stressors to which they were allegedly exposed..$^{25}$ The diagnosis is also often 
loosely applied by laypeople, as well as by professionals to patients who do not actually meet the required criteria for the disorder. For these reasons, psychiatrists should adhere strictly to the criteria laid down for this diagnosis. It is important to note that PTSD symptoms usually improve with time, so an extended period of appropriate treatment is indicated before the condition can be regarded as permanent. ${ }^{26}$ Also, many patients with persistent symptoms appear to have minimal functional impairment and are able to continue to function satisfactorily. Indeed, 50\% of active South African security force members were found to meet criteria for PTSD. ${ }^{27}$

Panic disorder with agoraphobia, social phobia and generalised anxiety disorder are often associated with avoidant behaviour that significantly impedes occupational and social functioning. However, these disorders often respond favourably to treatment, and re-exposure to the work environment may be an important part of management. Optimal treatment therefore needs to be applied for an extended period before these disorders should be regarded as permanent. Although obsessivecompulsive disorder is sometimes severely incapacitating, it can be effectively treated, making permanent disability unnecessary, notwithstanding the possibility of treatment resistance even after extensive therapy. ${ }^{22 \cdot 24}$

Schizophrenia, mood disorder with psychosis (bipolar or major depressive disorder), schizo-affective disorder, schizophreniform disorder, delusional disorder, psychotic disorder due to a general medical condition and substanceinduced psychotic disorder are usually associated with severe functional impairment during psychotic episodes. However, predicting chronicity and disability in schizophrenia and other psychotic disorders has only been moderately successful. Any decision regarding permanent disability should, however, be delayed until the best possible treatment outcome has been obtained. Factors such as the presence of residual symptoms (positive and negative), degree of insight, nature of employment and likelihood of relapse need to be considered. ${ }^{28}$

It is important that patients with cognitive disorders undergo full assessment to determine severity and chronicity, inclusive of reversible and irreversible damage. This includes appropriate special investigations, including brain imaging (computed tomography or magnetic resonance imaging scan) and neuropsychological testing. In the case of brain injury that may improve, a sufficient period of time (at least 2 years) should be allowed for recovery before considering permanent disability.

Disability applicants may present with physical complaints that cannot be fully explained by specific somatic diseases. When these symptoms are severe and disabling, and persist after specialist work-ups have failed to identify a cause, psychiatric assessment is often requested, resulting in diagnosis of a somatoform disorder such as somatisation disorder, chronic conversion disorder, pain disorder or hypochondriasis. Management of these patients should include education and psychotherapy aimed at helping the patient to understand the psychological mechanisms that appear to constitute the basis of their illness. The psychiatric report should comment on the patient's response to this treatment approach. Premature recommendations for boarding, without the patient being informed of the nature of their illness, may in fact prejudice recovery. ${ }^{29}$

Chronic fatigue syndrome is considered not to be a psychiatric disorder, and a mental disorder is an excluding criterion for diagnosing it. Symptoms such as depression, anxiety and cognitive impairment are often present, and the opinion of a psychiatrist may be sought to rule out the presence of a significant psychiatric disorder, including an undifferentiated somatoform disorder.

Epilepsy is also not considered to be a psychiatric disorder. Psychiatric grounds for disability may, however, arise when psychiatric sequelae of epilepsy (for example, psychotic disorder or cognitive disorder) are present.

Personality disorders are not usually regarded as a cause of permanent disability on their own.

\section{Ethical considerations Role conflict}

It is highly advisable that the treating psychiatrist does not formally assess his or her own patient for the purpose of disability application. ${ }^{30}$ The roles of therapist and formal assessor of disability are ethically different and even incompatible in some respects. Role confusion may lead to unwanted complications for both patients and clinicians. ${ }^{31,32}$ It may, for example, be in the patient's interests to maintain therapeutic role boundaries. From an ethical point of view it is also important that the assessor be an agent of the referral source and not principally of the patient.

\section{Informed consent and confidentiality}

As in all clinical evaluations, the psychiatrist is required to inform the person being evaluated of the nature and purpose of the examination and to obtain consent to proceed. The person should be informed that:

- The evaluation is not for treatment purposes and the person evaluated is not and will not become the psychiatrist's patient.

- The purpose of the evaluation is to provide an opinion about the person's mental state and level of impairment.

- The information and results obtained from the evaluation are not confidential, in that they will be shared with the referral source and may be disclosed to the court, administrative body or agency that makes the final decision regarding disability.

- The person evaluated should also be informed that the evaluation is voluntary. They should be advised of the right not to answer questions, but warned that refusal to answer specific questions may influence the evaluation and may be reported to the referral source. 
If a person does not agree to the conditions, the evaluation should not be undertaken. The person should be advised that refusal to proceed will be noted in the psychiatrist's report or testimony or reported to the referral source. ${ }^{21}$

Confidentiality of medical reports should be maintained at all times, by all parties involved. In view of the sensitive nature of some psychiatric reports, and the individual's rights in terms of the new South African Constitution and Bill of Rights, medical reports should be mailed or faxed directly to the medical officer only of the insurance company or employer involved, and marked as confidential. Under no circumstances should any medical report be handed over to an intermediary party, for example a broker, manager at work or personnel department. The patient must be informed that any information divulged may be included in the report.

If the psychiatrist deems it necessary to discuss aspects of the case with another party (such as the treating doctor or an employer), prior informed written consent must be obtained from the patient. Patients or their representatives are entitled to a copy of the psychiatrist's report. However, the report should be requested through the insurance company and only released with the psychiatrist's written permission. ${ }^{8}$

\section{Professional honesty}

According to rule 15.(1)(g) of the Health Professions Council of South Africa Guideline on Certificates of Illness, ${ }^{34}$ a certificate should include 'whether the patient is totally indisposed for duty or whether the patient is able to perform less strenuous duties in the work situation' Many patients in South Africa, as in all developed countries, are not completely disabled no matter how understandable their aversion to specific work circumstances. That applies to most employment categories, ${ }^{9,10}$ as well as to people in jobs with a high social and ethical responsibility - such as in the police force, military and teaching - who may be at particular risk of developing stress-related disorders?

Being honest in reporting the extent and nature of impairment should not be compromised or influenced by formal contractual agreements with the referral source, either to maintain employment or garner future referrals. That would be unethical. One should not be reticent in voicing an opinion that does not support the desired outcome of the referral source. ${ }^{21}$

\section{Unfair discrimination}

The Employment Equity Act of 1998 (Act No. 55) prohibits any person from unfairly discriminating against another person on grounds such as gender, age, race, religion and disability. ${ }^{35}$ In the area of disability evaluation, this will imply that all guidelines and criteria for disability assessment are evidence based, that claims assessment is undertaken fairly, objectively and consistently, that each individual claim is assessed on its own merit, and that no diagnosis will be handled with a 'broad-brush' approach.

\section{Consequences of medical boarding on psychiatric grounds}

Patients often do not want to hear about the option of rehabilitation, and are likely to shop around for a compliant doctor. They also often do not want to hear that resignation would be an appropriate and standard way of parting from an uncongenial work situation, because of the substantial financial benefits that they hope will go with a medically endorsed finding of disability.

Unfortunately patients may not appreciate the implications of medical boarding, which may result in additional financial difficulties and even ultimately regret and resentment. Together with the inactivity and loss of self-esteem associated with unemployment, these problems may compound their psychiatric difficulties and perpetuate their symptoms rather than facilitating recovery.

Patients should be informed that being medically boarded on psychiatric grounds is likely to make it extremely difficult to obtain alternative permanent employment, and even further insurance. Also, being medically boarded does not guarantee that the patient's medical disability policies will be paid out. The patient should be advised to obtain full details from the insurance company or broker beforehand about the conditions and requirements of these policies. The long-term financial implications should be discussed with a financial advisor. It would be prudent for psychiatrists to warn their patients that they may find themselves unemployed and without an adequate income, even when there are sufficient grounds for medical boarding. 8,10

Note furthermore that according to the Compensation for Occupational Injuries and Diseases Act (COIDA) 130 of 1993,36 disability assessment by the Compensation Commissioner is conducted according to specific rules and regulations that differ from the criteria applied by pension funds and the insurance industry in general. Medical boarding does not necessarily imply that the patient is entitled to additional awards under COIDA. Doctors advising patients on medical disability should therefore first consult the law and the regulations on the specific procedures to follow, as these can differ from other claims. ${ }^{8}$

\section{Rehabilitation}

In recent years there has been a growing awareness of and demand for vocational rehabilitation services. These may help to retain occupational capital, prevent unjustified vocational absenteeism, and contribute to a higher standard of practice. ${ }^{37}$

Many patients in South Africa with common psychiatric disorders are on medication and some also receive psychotherapeutic intervention. Psychiatrists should also consider the potential benefits of a supervised and mentored work rehabilitation programme. This should be set up in consultation with the employer and may involve an appropriate alternative position. Another option, if indicated, 
could be to return the employee to his or her duties in graded and/ or gradual way.

Occupational therapists are the most appropriate professionals to assist in such programmes. ${ }^{37}$ Although resources are limited and local health insurance benefits may be inadequate to cover the costs of ideal management, increased awareness of best practice should result in optimal utilisation of the available resources for retaining occupational capital in South Africa.

\section{References}

1. Bender A, Kennedy S. Mental health and mental illness in the workplace: diagnostic and treatment issues. Healthcare Papers 2004;5:54-67.

2. Fox DR. Observations on disability evaluation in the Social Security Administration. Journal of Social Behavior and Personality 1994;9:237-246.

3. Dewa CS, Lesage A, Goering P, Craveen M. Nature and prevalence of mental illness in the workplace. Healthcare Papers 2004;5:12-25.

4. Karpansalo M, Kauhanen J, Lakka TA, Manninen P, Kaplan GA, Salonen JT. Depression and early retirement: prospective population based study in middle aged men. J Epidemiol Community Health 2005:59:70-74.

5. Emsley R, Coetzer P. Disability claims on psychiatric grounds. South African Medical Journal 1996;86:646.

6. Emsley RA, Seedat S, Stein DJ. Posttraumatic stress disorder and occupational disability in South African Security Force members. J Nerv Ment Dis 2003;191:237-241.

7. Bauer J, Stamm A, Virnich K, et al. Correlation between burnout syndrome and psychological and psychosomatic symptoms among teachers. International Archives of Occupational Environmental Health 2006;79:199-204.

8. South African Society of Psychiatrists. Guidelines to the Management of Disability Claims on Psychiatric Grounds. 2nd ed. http://www.sasop.co.za/A_aboutus_Guidelines.asp (accessed 7 December 2010).

9. Smith ES. Work phobia and sickness leave certificates. African Journal of Psychiatry 2009;12:249-253.

10. Emsley R, Emsley L, Seedat S. Occupational disability on psychiatric grounds in South African school-teachers. African Journal of Psychiatry 2009:12:223-226.

11. ACOEM Guideline: Preventing needless work disabilities by helping people stay employed. J Occup Environ Med 2006;48:972-987.

12. Shiels C, Gabbay MB, Ford FM. Patient factors associated with duration of certified sickness absence and transition to long term incapacity. Br J Gen Pract 2004;54:86-91.

13. Van der Klink JJL, Blonk RWB, Schene AH, van Dijk FJH. Reducing long term sickness absence by an activating intervention in adjustment disorders: a cluster randomised controlled design. Occupational and Environmental Medicine 2003;60:429-4377.

14. Sawney P. Current issues in fitness for work certification. Br J Gen Pract 2002;52:217-222.

15. Harris I, Mulford J, Solomon M, Van Gelder JM, Young J. Association between compensation status and outcome after surgery: a metaanalysis. JAMA 2005;293:1644-1652.

16. Ewart Smith M. Work phobia: a psychiatric disability? S Afr Med J 1999;89:290-291.

17. Henderson M, Glozier N, Elliott KH. Long term sickness absence: is caused by common conditions and needs managing. (Editorial). BMJ 2005;330:802-803.
18. Dunstan DA. Are sickness certificates doing our patients harm? Aust Fam Physician 2009;38:61-63.

19. American Medical Association. Guidelines to the Evaluation of Permanent Impairment. 6th ed. Chicago: American Medical Association Press, 2007

20. American Psychiatric Association. Diagnostic and Statistical Manual of Mental Disorders. 4th ed., text revision. Washington, DC: American Psychiatric Association, 2000.

21. Gold LH, Anfang SA, Drukteinis AM, et al. AAPL practice guidelines for the forensic evaluation of psychiatric disability. Journal of the American Academy of Psychiatry 2008;36(suppl 4):S3-S50.

22. American Psychiatric Association Practice Guidelines. (2006). American Psychiatric Association: Washington, DC.

23. American Psychiatric Association. Diagnostic and Statistical Manual of Mental Disorders 4th ed., text revision. Washington, DC: American Psychiatric Association, 2000.

24. Saddock BJ, Saddock VA. Synopsis of Psychiatry: Behavioural Sciences and Clinical Psychiatry. 9th ed. Philadelphia: Williams \& Wilkins, 2003.

25. Rogers R, ed. Clinical Assessment of Malingering and Deception. New York: Guilford Press, 1997.

26. Brodsky CM. Factors influencing work-related disability. In: Meyerson AT, Fine T, eds. Psychiatric Disability: Clinical, Legal and Administrative Dimensions. Washington, DC American Psychiatric Press, 1987:49-65.

27. Kopel H, Friedman M. Posttraumatic symptoms in South African police exposed to violence. J Trauma Stress 1997;10:307-317.

28. Mohs RC, Lesser JC. Schizophrenia and disability. In: Meyerson AT, Fine T, eds. Psychiatric Disability: Clinical, Legal and Administrative Dimensions. Washington, DC: American Psychiatric Press, 1987:69-81

29. Epstein RM, Quill TE, McWhinney IR. Somatization reconsidered: incorportaing the patient's experience of illness. Arch Intern Med 1999;159:215-222.

30. Kaliski S. Psycholegal assessment in South Africa. Cape Town: Oxford University Press, 2006.

31. Strasburger LH, Gutheil TG, Brodsky A. On wearing two hats: role conflict in serving as both psychotherapist and expert witness. Am J Psychiatry 1997;154:448-456.

32. Appelbaum PS. Ethics in evolution: the incompatibility of clinical and forensic functions Am J Psychiatry 1997;154:445-44

33. Constitution of the Republic of South Africa. Bill of Rights, Chapter 2. 1996. http://www.info gov.za/documents/constitution/1996/index.htm (accessed 6 February 2012).

34. Health Professions Council of South Africa. Guideline on Certificates of Illness, 15.(1)(g). http://www.labourguide.co.za/general/medical-certificates-454 (accessed 6 February 2012).

35. The Employment Equity Act, Act No. 55 of 1998. Pretoria: Government Printer, 1998.

36. Compensation for Occupational Injuries and Diseases Act (COIDA). No 130 of 1993

37. Joss M. Occupational therapy and rehabilitation for work. British Journal of Occupational Therapy 2002;65(3):141-148.

\section{Recommended reading}

American Psychiatric Association Practice Guidelines. Washington, DC: American Psychiatric Association, 2006.

American Medical Association. Guidelines to the Evaluation of Permanent Impairment. 6th ed. Chicago: American Medical Association Press, 2007. Simon Rl, ed. Posttraumatic Stress Disorder in Litigation: Guidelines for Forensic Assessment. Washington, DC: American Psychiatric Press, 1995. Meyerson AT, Fine T, eds. Psychiatric Disability: Clinical, Legal and Administrative Dimensions. Washington, DC: American Psychiatric Press, 1987.

Rogers R, ed. Clinical Assessment of Malingering and Deception. New York: Guilford Press, 1997 